\title{
Linguistic Suggestion Through the Lens of Modern Arabic Political Discourse
}

\author{
V. Dudin \\ Taras Shevchenko National University of Kyiv, Ukraine \\ Corresponding author. E-mail: v.dudin@yahoo.com
}

Paper received 02.11.19; Accepted for publication15.11.19.

\section{https://doi.org/10.31174/SEND-Ph2019-211VII62-02}

\begin{abstract}
With cognitive science and suggestion playing an increasingly crucial role in day-to-day life of modern society through political discourse and media it is important to grasp an understanding of the types of suggestive elements used in various environments. In this article we propose various ways of classifying said suggestive elements within the scope of modern Arabic political discourse based on the strength of their potential impact, the type of impact, the place of use.
\end{abstract}

Keywords: Suggestion, Suggestive Elements, Political Discourse, Cognitive Linguistics.

The term "suggestion", has not observed significant changes in regards to its meaning, as used in this article, since it was first coined, in the sense used in this article, in the early XX century by professor V.M. Bekhterev. The term was first used at an assembly of the Saint-Petersburg Medico-Surgical Academy in 1897. It was later featured in the professor's study "Suggestion and Its Role in Social Life", published in 1903.

Bekhterev believed that the main purpose of his abovementioned study was to establish the term of "suggestion" as one completely separated in meaning from hypnosis or anything related to it. He supported this idea by pointing out the conditions under which an individual was influenced. In the case of hypnotic influence, the patient would typically be in a state of "special consciousness" and understand that attempts will be made to influence or control them, which leads to resistance from the patient. The level of such resistance would greatly depend on the depth level of the hypnosis and on the extent to which the hypnotism contradicts the ideas, perspectives and the positions of the recipient [3, p.26]. Thus "suggestion" could be defined as influence on a recipient who is wide awake (not in any kind of trance) and is likely unaware that he is being influenced, thus showing much less resistance, leading to potentially higher efficiency due to its comparatively inconspicuous nature.

It would no less important to establish what is implied by discourse. Aristotle wrote that "humans are political animals" and are therefore capable of using language for the sake of achieving clearly established selfish goals [2, p. 5]. Aristotle clearly differentiates speech from voice as he argues that "man is the only animal whom [nature] has endowed with the gift of speech..., the power of speech is intended to set forth the expedient and inexpedient, and therefore likewise the just and the unjust" [2, p. 5]. Humans are able to express numerous varieties of information through speech (from expressing emotion to communicating danger or interest).

P. Chilton in his work "Analysing Political Discourse: Theory and Practice" refers to R. Hague and others to state that politics imply reconciliation of differences through discussion and persuasion, thus making communication central to politics [4, p.4].

If we compare politics to economics, political discourse can also be conditionally divided into the institutional/global "macro" level and the personal/local "micro" level. Within the former we include governments, governmental bodies, big business, international organisations, highly influential individuals. On this conditional macro plane, discourse is executed through a complex communicative process between its representatives with the goal of resolving conflicts through political pressure or the possibility of reaching a mutually beneficial agreement for all of the parties involved. Within this plane, specific individuals usually only play the roles of managers of said institutions: ministries, companies, organisations, parties, civil movements, charities.

On the macro level the above-mentioned influence between these institutions is typically exercised through official documents (e.g. official letters, memorandums, etc.) and meetings behind closed doors. The participants of such meetings can include both delegations and separate management representatives or the authorised personnel of such institutions.

Which leads to an important conclusion well described by Chilton: "What is strikingly absent from conventional studies of politics is attention to the fact that the micro-level behaviours mentioned above are actually kinds of linguistic action - that is, discourse" [4, p.4].

On the other hand, examples of discourse on the conditional "micro" level described above tend to include the following: political debates, presentations, political and advertisement videos, interviews, press-conferences. Amongst the more recently relevant we have posts/publications on Social media. This type of discourse would usually concern protection and/or promotion of personal interests or a specific element rather than the general interests of an institution or organisation.

While not a highly frequent occurrence, discourse carried out on the micro level may end up influencing the macro level, such as in the case of the $45^{\text {th }}$ US president - Donald Trump, who, on multiple occasions throughout his presidency, posted his personal opinion on his personal twitter account. This can occasionally lead to political pressure during talks on the macro level as he transforms his personal statements into reflections of his policies, given his position as the head of state.

Nonetheless, participants of political discourse on the above-mentioned conditional "macro" level rarely take notice of the weight of individual fragments of their communications, referring to in depth analysis of their words as "nit-picking". However, these exact same macro-level representatives would be unlikely to support the notion that a politician's words have no meaning and/or value. Therefore, this supports the idea of politics and speech being interconnected.

Background. Political discourse in the Arab world can be observed in its oral forms (speeches, press-conferences, public statements, videos on social media, etc.) and written varieties (articles, critiques, written publications/posts on social media, literary activity, online forums and discussions, etc.). 
In the Arab world political discourse has existed in the PreIslamic period, however it would be rather complicated to provide an objective assessment of its development during this period. A significant part of frequent armed conflicts on the local level happened without much or any preceding discussions or negotiations. Nonetheless, the Arabic language has always differentiated itself with the large variety of synonyms and style, which have played a role in the development of Arabic political discourse. Throughout the Pre-Islamic period or Jāhilīyah (الجاهلية), as it is also known in Arabic, we can observe the rise of the qașīda (قصيدة). Beyond its literary and artistic value, it was also an efficient method used in political discourse to, for example, improve one's reputation and increase respect with the panegyric genre (مدح) or to doubt the achievements and reputation of the other party through the Hijā' genre (هِجَاء) - a form of satire. The etymology of the word "qașīda" has changed with time - before meaning "poem" or "ode", it used to mean "intent". This quite accurately indicates the reasoning for writing such works - the intent of the poet to share a specific perception with others [5].

Throughout the Islamic period, considered by some scholars as the golden age of the Arab world, the use of qașidas with the intent of influencing the reputation of its character(s) reaches its peak and effectiveness in its history [8]. Hārūn ArRašīd, Sayf al-Dawla, 'Aḍud al-Dawla have all lived at various periods during this age and they had qașīdas written about them by such classics as Abū t-T Tayyib al-Mutanabbī and Abū 1-'Atāhiyya, however these names do not begin to describe the extensive list of historical figures who lived throughout this period. Through the works gaining popularity and spreading within the empires, the poets would not only increase the reputation of their patrons, but would also amplify the fear of the empire's enemies, while maintaining or even improving the morale and devotion of their followers.

The Arabic language enters the post-golden age with a standardised form, which was widely understandable by all Muslims, despite the existence of a multitude of local dialects. Throughout this timeframe, the Arab world's regional dominance was overthrown, with most of the territories ending up under control of foreign empires, which would utilise political discourse typical for their languages and cultures. According to the library exhibits of Yale University, "the establishment of the Arabic printing presses in the Ottoman Empire was delayed due to the fear of the sultans that some biased persons might tamper with the sacred religious texts. Hence, in 1485 Sultan Bayezid II (1447 or 8-1512) issued a royal decree prohibiting the use of printed books. A similar decree was issued in 1515 by the Sultan Selim I (1470-1520)". These limitations would only concern Muslims. The efforts to open the first Arabic printing press within the empire were successful only around 300 years later and this printed press would be primarily focusing on language and religion [6]. On the other hand, the foundation of the Arabic printed press in Egypt, while under French occupation led by Napoleon, was motivated primarily by political motives: printing political pamphlets, spreading political ideas and ideologies of the coloniser amongst the few who were able to read in Egypt of that time period. Nonetheless the efforts of the French colonisers in printing propaganda marked the point of time when written Arabic political discourse clearly came into existence, despite the non-Arabic values it was being used to spread at the time.

Therefore, there were few events that could lead to further development of discourse in Arabic under these conditions.
Later, with the beginning of the Arab Renaissance also known as "an-Nahḍa" (النهضي), while under control of colonial empires, would bring never before seen importance to Arabic political discourse, as Arabic becomes the language of political ideas voicing independence, shared both through literature and political speeches.

Since the start of XXI, political discourse has found yet another arena for development - the internet. Within this plane, a bigger need of acquiring and retaining the viewer's attention has come to light for a number of previously non-existent reasons. Firstly, the quantity of publicly available information as grown exponentially since the World Wide Web opened to the public. This is true for both the scientific information and research as well as more subjective varieties of information. With limited time and much more information available than can be possibly consumed within that timeframe, an active fight for users begins, primarily amongst publishers of nonacademic information. The rise of the possibility of anybody being able to share a subjective point of view in textual, audio or video formats, with the right technology and if in the possession of the required technical means, represents the beginning of the next stage of political discourse. Monologues aside, the appearance of public discussion boards adds the potential for instantaneous reaction of the viewers, with this reaction itself also becoming part of political discourse. Publications in social media and reactions to these publications have also become crucial to understanding and changing the political landscape with language.

The internet overall and social media in particular have politicised our lives through saturation by subjective and/or politicised information. In the Arab world, media corporation Al-Jazeera, has been accused by competitors on numerous occasions of propagating the interests of the Qatari state. These accusations have become part of the reason behind the AlJazeera network getting blocked partially or completely in a number of countries (e.g. Egypt, Saudi Arabia...) [1,9]. With an increase of information, it becomes ever more difficult to hear the thoughts of an individual, excluding those who are celebrities or occupy a position (president, head of a multinational, etc.), which is deemed to be of great importance for a political or socio-economic reason amongst others. However, as we stated above, the latter are part of the macro level, where it is much easier to be heard thanks to the size and weight in society. As we move forward, the effectiveness of information in its ability to send the message across in this cluttered reality will likely have a higher level of reliance on suggestive elements, therefore we believe it to be important to present a brief overview of different environments and kinds of such suggestive elements.

Classification of Suggestive Elements by Strength of Impact. Suggestive elements can be of various strength levels. In fact, the linguistic means of suggestion can be placed on a gradient in terms of strength of their impact. We have made an attempt to provide a sufficiently clear description of some of the points on this gradient, which, in our opinion can be most easily distinguished.

i. On the farthest end of the weak spectrum we have the "non-existent impact" category. This category contains elements, which do not carry any suggestive impact and cannot have any subjective connotation. There is no way to transfer an opinion or position on a subject solely with these words. 
Examples of such Arabic linguistic units, which can be related to the "non-existent impact" category include the following:

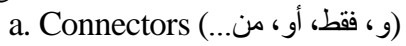

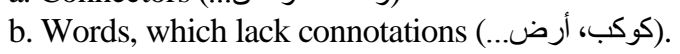

c. Numbers (عانشر، واحد...)

It is worth noting that we have outlined this category to establish that not all units, which can be found in socio-political articles should be immediately considered to have suggestive properties in their stand-alone forms.

ii. Moving along the spectrum we find the "background impact" category. We have assigned to this category those linguistic units, which demonstrate weak suggestive properties if repeated numerous times throughout a speech or within a text.

Examples of such Arabic linguistic units, which can be related to the "background impact" category include the following:

a. Personal pronouns, which are inferred, but are not written (ضمير مسنتر), excluding the plural form of the first-person.

b. Personal pronouns, which are written through affixation, specifically by adding a corresponding suffix (ضمير متَّصل), excluding the plural form of the first-person.

Repeated usage of elements, which are a part of this category may result in a minor suggestive effect on the recipient of such information. Usually such elements would be complementing those with more pronounced connotations.

iii. Further along the spectrum there is the "insignificant/minor impact" category. Elements, which form part of this group, will have a basic, albeit weak property to influence people even in case of single-time use, however will rarely be purposely used without being accompanied by elements with stronger suggestive properties.

Below we bring a few examples:

a. Linguistic units with slight emotional associations: various positive (for example - أسرة, translated as "family", which tends to bring positive associations of hope, happiness and respect), as well as negative (for example - مَطَر , which translates to rain, and brings associations of pessimism, sadness).

b. Personal pronouns in the form of separate words ( ضمير (منفصل) in third person.

c. Personal pronouns indicating respect (ضمير الثأن) in third person.

Even within this group of just three examples, one can see a number of perspective synergies, where the first example can create a specific, albeit rather weak, emotional setting and the second group can relate it to a particular person.

iv. As we continue towards the other side of the spectrum, we find the category composed of units with a relatively high level of potential suggestion.

Amongst examples of elements, which form this category, the following are worthy of notice:

ضمير ( ض. Personal pronouns in the form of separate words (منفصل in the plural form of first person. The suggestive "we" plays a significant role in forming the impression that the reader and author are on the same side in regards to the subject matter.

b. Repeating proper nouns multiple times throughout the oral or written piece of information, thus tying that proper noun to the information/mood conveyed on a cognitive level of the recipient.

c. References to previous events for emphasis and contrast

Repetition is one of the comparatively effective ways of tying an emotion with a source, which plays a crucial role in increasing the effectiveness of the suggestion. Moreover, repetition is just an example of the many potential suggestion tactics, which could be described as having a relatively high potential for suggestive impact.

v. Finally reaching the opposite end of the spectrum we find ourselves in the "direct/significant impact" category. This category comprises of linguistic units with the highest potential suggestive impact capabilities. Each of the words, which are part of this category have a clear impact, as these words tend to have a single and stable connotation. This can be represented by both words with a clear positive (جميل - translated as "beautiful") or negative connotation (موت - translated as "death").

While the units, which are part of this category are undoubtedly efficient they may, if used at a high frequency, become equally evident for the recipient, which therefore leads to a need in moderation when using words from this category.

Beyond the one-word examples provided in this study for simplicity purposes, phrases or even narrative types can sometimes fall into a particular category. An example of the latter could be a narrative aimed at discrediting a particular party.

Overview of Suggestive Elements by Type of Impact. The type of impact suggestion can have may also be viewed on a spectrum ranging from negative (pathogenic) to positive (therapeutic) varieties. In order to optimise the description of this spectrum, we have attempted to describe the far ends of the spectrum, as well as the mid-point.

Pathogenic or negative suggestion represents conscious information activity, aimed at accentuating a negative overview and assessment of facts and events, which concern or are relevant for the described situation. The pathogenic suggestion frequently requires active usage of corresponding linguistic units, which cause negative associations and emotions and then link them with the subject matter of the corresponding information piece.

Nonetheless, pathogenic suggestion in its spectrum represents an effective means of provoking action aimed towards bringing change, counteracting the current state of affairs. Negative suggestion frequently uses fear for the purpose of increasing and holding the recipient's attention, improving the effectiveness of the target communicative message.

The neutral part of the type spectrum represents elements, which are part of one of the two following categories:

a) Linguistic units with suggestive properties, however they act as amplifiers and have no connotation of their own when used in a separate format, taking on the connotation of the collocations and the text overall.

b) Linguistic units with a minimal or non-existing level of suggestive impact therefore removing them from either ends of the spectrum.

Most words in their separate state are part of the neutral type of impact category. However, most of these neutral units are part of the above-mentioned category (a) and therefore change their suggestive connotation depending on the information field in which they are in.

Therapeutic or positive suggestion represents the opposite end of the spectrum. Therapeutic suggestion had been used during times of wars in order to calm down and improve morale of both the civil and military parts of the population, this can be paralleled to extended period of crisis. This became of especially high importance in the case of prolonged largescale conflicts. There are many possible applications and types of therapeutic suggestion in the socio-political 
information plane. One of the classic examples of such suggestion is the description of proactive and positive activity of the state on state-owned or current government-favouring media outlets.

Exploring Suggestive Elements by Place of Impact. Amongst the suggestive means typical for Arabic there are those, which are primarily used for a particular application, since they may require certain conditions to be satisfied in order to achieve maximisation of effectiveness.

Separating the field of use of specific varieties of suggestive communication into the written and oral forms requires particular attention, since Arabic has a developed tradition of public speaking and eloquence typical for each respective style: from the journalistic and political to the literary variety.

Public speaking has existed for thousands of years and represented communicative activity of tribe leaders with their subordinates for the purpose of transmitting commands and/or motivation. We cannot exclude the importance of non-verbal elements in the amplification of suggestion effectiveness, especially during the more distant Pre-Islamic periods, when the language was not yet as sophisticated as the modern-day Arabic.

Later, the development of literature also brought public prose readings, including saj' (سجع), a type of rhyming prose, which were educational and/or informational, or, perhaps more frequently had a recreational purpose. Poetry, representing a more complex format of a literary craft, as it introduced form limitations, came as a next step in the evolution of public readings.

Suggestive properties of the oral format frequently are associated not just with the charisma of the speaker, but also with the eloquence of what is being said. Eloquence impacts the ability of this information to leave a mark on the recipient's memory and therefore increase the chance of this information being spread further. The issue of spreading suggestive information throughout the earlier periods lied in the highly fragmented nature of the territories due to a large number of tribes, some of which are in a state of constant war with one another. Thus, the radius of the potential information spread was largely restricted by the neighbouring tribes. However, there were exclusions to the rule, the most famous of which are perhaps the $\mathrm{Mu}$ 'allaqāt, which were said to have hung on or in the Kaaba at Mecca as examples of the best poetic works of the time. There is however an opinion, amongst some scholars, that they never physically were hung in the physical sense of the word, rather that they hung on the memory of the people, thus explaining the reason for their widespread nature in Pre-Islamic Arabia [7].

With the passage of time, certain tribes formed tribe alliances, later becoming countries and empires and with each decrease in administrative fragmentation in the region the speed increased and range of the information circulation expanded. Later, with the arrival of printed press and modern technologies, there was a further significant never before seen increase in range and speed.

The written format boasts an even wider spectrum of styles from the formal to the journalistic to the literary with the main difference between the oral and written places of use of suggestion lying in the prosodic elements, in particular the pauses, rhythm, intonation and tonality, which exist solely for the oral varieties. While rhythm is technically present in the qașīda, this type of rhythm is rather a form requirement than a potential suggestive property.

This notion also warrants the fact that suggestion in the written forms has higher levels of importance due to lack of impact from factors such as charisma and/or prosodic elements. In this case charisma would be somewhat substituted with eloquence, as there remains a need to retain the reader's attention in order for any kind of suggestion to have at least a moderate effect.

Conclusion. Given the fast-moving and informationally dense world we currently live in it is important to understand what differentiates one piece of information from the other, what makes it stick to the readers mind and why can you be persuaded more easily by certain information. The Arabic political discourse had a late start, but is currently on the same stage of development as its older counterparts, as it strives to adapt to the new realities. Suggestive units in Arabic political discourse exist in various forms, strength levels and types of impact and tend to be more critical for written pieces of information.

Further research in this field is warranted given the importance of this topic in the current informationally rich environment. We will need to carry out more detailed studies on the exact types of suggestive units within a particular form of information to apply the findings we have noted here and further expand on them with more detail.

\section{REFERENCES}

1. Aboulenein A. Egypt blocks 21 websites for 'terrorism' and 'fake news' [Last accessed on November 1, 2019]/Ahmed Aboulenein // Reuters. - 2017. - Режим доступу до ресурсу: https://www.reuters.com/article/us-egypt-censorshipidUSKBN18K307.

2. Aristotle. Politics. (Translated by: Benjamin Jowett). Kitchener: Batoche Books, 1999. - p. 192

3. Bekhterev, V.M. Vnushenie i ego rol' v obshhestvennoj zhizni./Bekhterev, V.M. - Saint-Petersburg: K.L. Rikker Publishing House, 1903. - p. 144.

4. Chilton P. Analysing Political Discourse: Theory and practice/Paul Chilton. - London: Routledge, 2004. - p. 241.

5. Motoyoshi Sumi A. Description in Classical Arabic Poetry: Waòsf, Ekphrasis, and Interarts Theory/Akiko Motoyoshi Sumi. - Leiden: Brill, 2004. - p. 251.

6. Printing History in the Arabic-Speaking World [Last accessed on November 1, 2019] // Yale University Library - Available from: http://exhibits.library.yale.edu/exhibits/show/arabicprinting/printing_history_ arabic_world.

7. Robson, J. The Meaning of the Title "Al-Mu'allaqāt"// The Journal of the Royal Asiatic Society of Great Britain and Ireland, 1936. (1), pp. 83-86.

8. The Golden Age in Islam [Last accessed on November 1, 2019] // KAUST Museum of Science and Technology in Islam - Available from: http://museum.kaust.edu.sa/docs/KAUST_Leaflet.pdf.

9. Websites of Al Jazeera, Qatari newspapers blocked in Saudi Arabia and UAE [Last accessed on November 1, 2019] // al-Arabiya. 2017. - Available from: http://english.alarabiya.net/en/media/ digital/2017/05/24/Websites-of-Al-Jazeera-Qatari-newspapersblocked-in-Saudi-Arabia.html. 